\title{
Autoshaping: Relation of feeder color to choice of key color
}

\author{
MARY ANN FISHER and A. CHARLES CATANIA \\ University of Maryland Baltimore County, Baltimore, Maryland 21228
}

\begin{abstract}
In a two-key autoshaping procedure with pigeons, sessions consisted of 60 trials in which the simultaneous presentation of a red key and a green key was followed by operation of the feeder. In some sessions the feeder light was red; in others it was green. On the first session of exposure to this procedure, pigeons' autoshaped pecks occurred first and predominantly on the key whose color matched the feeder color, and this preference was resistant to change when, for each pigeon, the other feeder color was used in a second session. With other pigeons, the first autoshaping session with a given feeder color was preceded by a session of feeder presentations alone (no keys) with the other feeder color. For these pigeons, key-color preferences were inconsistent. A formal model is used to assess the contributions of generalization and overshadowing to these data.
\end{abstract}

The temporal correlation of key stimuli and feeder presentations is a necessary condition for autoshaped keypecking by pigeons (Brown \& Jenkins, 1968; Gamzu \& Williams, 1973), but the present results indicate that it is not a sufficient condition. In particular, when two different keys simultaneously precede food deliveries, autoshaped pecks may occur on only one of them. Pecks are directed first and overwhelmingly to the key that shares more properties (e.g., color) with the stimuli that accompany food delivery. The key preference thus established is durable and resistant to change, but the establishment of this strong preference can be prevented. The details of the data suggest that principles useful in other contexts, generalization and overshadowing, may serve well to order and summarize these findings. A formal model for the effects of cumulative trials on subsequent keypecking shows how both of these principles contribute to an effective description of these performances.

\section{METHOD}

\section{Organisms and Apparatus}

Twenty-four experimentally naive adult male White Carneaux pigeons were maintained at about $80 \%$ of free-feeding body weight. On the day preceding its first experimental session, each pigeon was given a 40-min adaptation session with houselight on in the experimental chamber. The chamber panel included two translucent $2.0-\mathrm{cm}$ Gerbrands keys mounted $6.5 \mathrm{~cm}$ apart, center to center, and $22.5 \mathrm{~cm}$ above the chamber floor. Each key required a minimum force of $.13 \mathrm{~N}(13 \mathrm{~g})$ and could be lit from behind by red or green 6-W ac Christmas-tree lamps. The standard Gerbrands feeder was centered below the keys, and its aperture was lit by either a red or a green lamp when the feeder

The authors wish to thank Robert Koontz, Marian Owens and Marvin Newhouse for their assistance in this study. Data and theory reported in this paper were presented in summary form by the first author at the 1975 Eastern Psychological Association meeting. For reprints, write the first author at the Department of Psychology, University of Maryland Baltimore County, 5401 Wilkens Avenue, Baltimore, Maryland 21228. was operated. The houselight, lit throughout each session, consisted of a white $6-\mathrm{W}$ ac lamp located behind a $2.5-\mathrm{cm}$-square translucent window at the upper right corner of the panel. Electromechanical scheduling and recording equipment was located in a separate room.

\section{Procedure}

For one group of pigeons, adaptation was followed on the next day by an autoshaping session. For Pigeons 1, 2, 7, 20, 21, and 22 , the light that accompanied feeder operation was red; for Pigeons $8,9,10,11$, and 17, it was green. At the beginning of the session, the feeder was operated and lit, with grain topping up the feeder opening, until the pigeon had eaten for $30 \mathrm{sec}$. On the next feeder presentation, the feeder was operated until $5 \mathrm{sec}$ after the pigeon began eating. This procedure was continued until eating began within 2 or $3 \mathrm{sec}$ of each feeder presentation, but in most cases a single feeder presentation was sufficient to satisfy this criterion.

Sessions consisted of 60 trials. Each trial was made up of a $40-\mathrm{sec}$ intertrial interval, a 5 -sec presentation of the two lit keys in which the positions of red and green on the left key and right key varied irregularly from trial to trial, and a 5-sec feeder operation (or longer, if the feeder-training criterion had not yet been met). For Pigeons 7, 10, and 22 the key lights remained on during the feeder operation. The houselight was on throughout each component of each trial, and keypecks never had any scheduled consequences. On the next day, a second 60-trial autoshaping session was conducted, but with the red and green feeder colors reversed for each pigeon.

For a second group of pigeons, the session following adaptation consisted of feeder training followed by 60 trials of feeder presentation alone. Successive feeder presentations were separated by a 35 -sec intertrial interval. In other words, the procedure differed from that for the first group only in that no lit keys were presented. For Pigeons $3,5,14,16$, and 18, the light that accompanied feeder operation was red; for Pigeons 4,6 , 13,15 , and 24 , it was green. On the next day, a 60-trial autoshaping session was conducted, but for each pigeon the red or green feeder color was reversed from that in the feeder-only session.

These conditions permitted comparisons of autoshaped keypecking with a given feeder color, red or green, when the preceding session included adaptation only (initial autoshaping session for the first group), feeder training with the other feeder color only (initial autoshaping session for the second group), or keypecking autoshaped with the other feeder color only (second autoshaping session for the first group). 
Table 1

Data for Each Pigeon in Each Condition

\begin{tabular}{|c|c|c|c|c|c|c|c|}
\hline \multirow{2}{*}{$\begin{array}{l}\text { Prior } \\
\text { Condi- } \\
\text { tion }\end{array}$} & \multirow[b]{2}{*}{ Pigeon } & \multicolumn{2}{|c|}{$\begin{array}{c}\text { Trial of } \\
\text { First Peck }\end{array}$} & \multicolumn{2}{|c|}{$\begin{array}{c}\text { Number } \\
\text { of Trials } \\
\text { With Pecks }\end{array}$} & \multicolumn{2}{|c|}{ Total Pecks } \\
\hline & & Green & Red & Green & Red & Green & Red \\
\hline
\end{tabular}

Keys + Red Feeder*

\begin{tabular}{|c|c|c|c|c|c|c|c|}
\hline & & & & & & & \\
\hline & 1 & 31 & 8 & 1 & 48 & 1 & 301 \\
\hline & 2 & (61) & 5 & 0 & 42 & 0 & 128 \\
\hline Adapta- & 7 & (61) & 48 & 0 & 10 & 0 & 23 \\
\hline tion & 20 & 17 & 16 & 3 & 37 & 3 & 141 \\
\hline & 21 & 41 & 37 & 1 & 9 & 2 & 11 \\
\hline & 22 & 17 & 14 & 5 & 39 & 10 & 262 \\
\hline & 4 & 19 & 20 & 3 & 6 & 5 & 8 \\
\hline Green & 6 & 45 & 55 & 1 & 3 & 1 & 3 \\
\hline Feeder & 13 & 14 & 7 & 3 & 35 & 3 & 107 \\
\hline Only & 15 & 19 & 24 & 1 & 35 & 1 & 272 \\
\hline & 24 & 24 & 30 & 24 & 17 & 51 & 40 \\
\hline & 8 & 1 & 9 & 15 & 9 & 24 & 18 \\
\hline Keys + & 9 & 1 & 4 & 54 & 7 & 310 & 23 \\
\hline Green & 10 & 4 & 3 & 6 & 16 & 6 & 22 \\
\hline & 17 & 2 & 13 & 30 & 22 & 102 & 57 \\
\hline & & $y s+C$ & $\mathrm{Fe}$ & er* & & & \\
\hline & $\begin{array}{l}8 \\
9\end{array}$ & 22 & $\begin{array}{c}(61) \\
35\end{array}$ & 28 & 0 & $\begin{array}{l}142 \\
258\end{array}$ & $\begin{array}{l}0 \\
5\end{array}$ \\
\hline Adapta- & 9 & 9 & 35 & 41 & 4 & 258 & \\
\hline tion & 10 & 15 & 58 & 16 & 1 & 23 & 2 \\
\hline & 11 & 7 & 8 & 41 & 1 & 126 & 1 \\
\hline & 17 & 8 & (61) & 2 & 0 & 2 & 0 \\
\hline & 3 & 20 & 30 & 20 & 19 & 40 & 44 \\
\hline Red & 5 & 37 & 1 & 5 & 9 & 9 & 16 \\
\hline Feeder & 14 & 30 & 20 & 8 & 21 & 8 & 53 \\
\hline Only & 16 & 6 & 7 & 13 & 8 & 20 & 11 \\
\hline & 18 & 52 & 58 & 2 & 1 & 2 & 1 \\
\hline & 1 & 14 & 2 & 13 & 50 & 20 & 254 \\
\hline Keys + & 2 & (61) & 2 & 0 & 50 & 0 & 109 \\
\hline Red & 20 & 11 & 3 & 6 & 48 & 14 & 129 \\
\hline Feeder & 21 & 7 & 2 & 3 & 53 & 3 & 153 \\
\hline & 22 & 11 & 2 & 4 & 45 & 4 & 161 \\
\hline
\end{tabular}

Note-Trial of first peck is entered as (61) when no peck occurred on that color key in the 60-trial session. Pigeons 12, 19 , and 23 did not complete an autoshaping session and Pigeons 7 and 11 did not proceed to a second session.

*Current condition

\section{RESULTS}

The data for each pigeon are summarized in Table 1. In the first autoshaping session for the first group (prior condition: adaptation), the first autoshaped peck occurred on the key color that matched the current feeder color for each of the 11 pigeons. For example, for Pigeon 1 (red feeder), a red-key peck occurred on Trial 8 and only a single green-key peck occurred in the session on Trial 31 ; for Pigeon 8 (green feeder), a green-key peck occurred on Trial 22 and no red-key pecks occurred throughout the session. After the first peck, subsequent pecks also occurred predominantly on the key color that matched the current feeder color for each pigeon.

When autoshaping was preceded by a session of feeder training with the other feeder color (prior condi- tion: other feeder color only) in the second group, pecking did not occur systematically on the key color that matched the current feeder color. For example, Pigeon 4 (red feeder) first pecked a green key on Trial 19 and a red key on Trial 20; Pigeon 3 (green feeder) first pecked a green key on Trial 20 and a red key on Trial 30 . For some pigeons, pecks predominated on the key color that matched the current feeder color (e.g., Pigeons 13, 15, and 16), but this effect was inconsistent within the group. In other words, prior exposure to the other feeder color attenuated the direction of pecking to the key color that matched the current feeder color in this autoshaping group.

When autoshaping was preceded by a session of autoshaping with the other feeder color (prior condition: keys plus other feeder color), pecking began and continued predominantly on the key color that matched the earlier feeder color rather than the one that matched the current feeder color. For example, Pigeon 8 (prior green feeder and current red feeder) pecked a green key on Trial 1 and first pecked a red key on Trial 9, and green-key pecking was more frequent than red-key pecking; Pigeon 1 (prior red feeder and current green feeder) pecked a red key on Trial 2 and a green key on Trial 14, and red-key pecking predominated throughout the session (this pigeon changed over from pecking red to pecking green on four trials during this session: cf. number of trials with pecks; changeovers were otherwise rare in these procedures). Within the group, Pigeon 10 provided the only exception to the predominance of pecking on the key color that matched the prior feeder color. Nevertheless, except for Pigeon 2 (current green feeder but no green-key pecks), this condition also did generate pecking on the key color that matched the current feeder color for all pigeons.

Although some pigeons showed idiosyncratic leftvs right-key preferences, no consistent side preferences attributable to the apparatus were obtained within groups. Red-key pecking tended to be greater than green-key pecking under equivalent conditions. For example, with current feeder color red, the mean total red-key pecks for the three prior conditions were, respectively, 144, 86, and 30 pecks; with current feeder color green, the corresponding mean total green-key pecks were 110,16 , and 8 pecks, respectively. Because no attempt was made to equate the red and green key lights for intensity or for intensity weighted by spectral sensitivity, no conclusions can be drawn from the present data on the source of this difference.

\section{DISCUSSION}

Autoshaped keypecks are affected by both generalization and overshadowing. Tables 2 and 3 present data from Table 1 reorganized to support this conclusion. These will be discussed first. A formal model of the experiment incorporating these processes will then be presented and the extent to which generalization and overshadowing can account for the mean number of trials each key was pecked during the session will be evaluated. 
The model is an application of Fisher's (Note 1) model of twochoice visual discrimination learning.

\section{Generalization}

The key-of-first-peck data show that, given two keys that were equally good temporal predictors of food, the first peck was directed to the key of the same color as the feeder, 11 to 0 . This key-feeder similarity effect was absent in birds who had previous unsignaled presentations of the other-color feeder. These birds preferred the more similar key 4 to 6 (Fisher's exact test, $p=.004)$. This result suggests two possibilities: Either similarity of key and feeder increased the effectiveness of temporal pairing or pecks were conditioned to cues of the feeder and generalized to the keys on the basis of similarity. One or the other, or both, were operating here. Generalization on the basis of similarity of feeder and key can also account for the results reported by Downing and Neuringer (1976), showing apparent pseudoconditioning of keypecks following 100 or fewer unsignaled feeder presentations.

\section{Overshadowing}

The mean-trial-of-first-peck data in Table 2 demonstrate the overshadowing of the second-pecked key. The average trials between the first peck on the first-pecked key and the first peck on the other-color key were significantly fewer for birds with than without previous unsignaled feeder experience (median test, chi square $=4.32, p<.05)$. The first keypeck was not delayed by the previous unsignaled feeder experience: It occurred in a mean of 17.2 trials for the group with no previous feeder experience, which is not statistically different from the mean of 21.3 trials for the other group. Downing and Neuringer (1976) found similar results, with no apparent delay of autoshaped keypecks after unsignaled feeder presentations over a range from 1 to 100 presentations. In calculating this delay between the first peck to each key in the first autoshaping session, the estimation of 41.0 trials is conservative; four birds gave no pecks to the other key and were assigned the arbitrary value of Trial 61 . This delayed pecking when a key that predicts food is presented simultaneously with a preferred key suggests overshadowing.

The mean pecks per session on each key, in Table 4, are consistent with the earlier observations and provide additional evidence for overshadowing. In the bottom group, the preference established in the first autoshaping session persisted even after the color of the feeder had changed. This cannot depend simply on experience with the other-color feeder, since the effect was absent in the middle group. The lesser responding to the newly similar key resulted from the strong preference established for the other key in the first autoshaping session.

\section{The Formal Model}

The model proposed to account for aspects of the present data is an application of a more general model (Fisher, Note 1) incorporating concepts similar to those developed by Rescorla (1972) and Wagner (1970) in other contexts. The equations of the model involve three processes: association by temporal contiguity, generalization, and overshadowing. Two equations describe the effects of the events of a trial on the tendency to peck a particular key:

Table 2

Mean Trial of First Peck

\begin{tabular}{cccc}
\hline $\begin{array}{c}\text { Previous } \\
\text { Experience }\end{array}$ & $\begin{array}{c}\text { Key of } \\
\text { First Peck }\end{array}$ & Other Key & $\begin{array}{c}\text { Mean Delay } \\
\text { in Trials }\end{array}$ \\
\hline $\begin{array}{l}\text { Adaptation } \\
\begin{array}{l}\text { Other Color } \\
\text { Feeder Only }\end{array}\end{array}$ & 17.2 & 41.0 & 23.8 \\
\hline
\end{tabular}

Table 3

Mean Number of Pecks Per Session

\begin{tabular}{|c|c|c|c|c|}
\hline \multirow[b]{2}{*}{ Previous Experience } & \multirow{2}{*}{$\begin{array}{c}\text { Feeder } \\
\text { Color }\end{array}$} & \multicolumn{2}{|c|}{ Key Color } & \multirow{2}{*}{$\begin{array}{c}\text { Percent } \\
\text { Pecks to } \\
\text { Similar } \\
\text { Key }\end{array}$} \\
\hline & & Red & Green & \\
\hline $\begin{array}{l}\text { Adaptation } \\
\text { Adaptation }\end{array}$ & $\begin{array}{l}\text { Red } \\
\text { Green }\end{array}$ & $\begin{array}{r}144 \\
3\end{array}$ & $\begin{array}{r}2 \\
110\end{array}$ & 98 \\
\hline $\begin{array}{l}\text { Green Feeder Only } \\
\text { Red Feeder Only }\end{array}$ & $\begin{array}{l}\text { Red } \\
\text { Green }\end{array}$ & $\begin{array}{l}86 \\
12\end{array}$ & $\begin{array}{l}25 \\
16\end{array}$ & 73 \\
\hline $\begin{array}{l}\text { Green Feeder + Keys } \\
\text { Red Feeder + Keys }\end{array}$ & $\begin{array}{l}\text { Red } \\
\text { Green }\end{array}$ & $\begin{array}{r}30 \\
110\end{array}$ & $\begin{array}{r}161 \\
8\end{array}$ & 12 \\
\hline
\end{tabular}

Effect of key-feeder pairing:

$$
r_{n}=p_{n}+a \theta_{1}\left(1-p_{n}\right)\left(1-p_{n}^{\prime}\right)
$$

Effect of feeder presentation:

$$
p_{n+1}=r_{n}+a \theta_{2}\left(1-r_{n}\right)
$$

Models of this type generally incorporate learning-rate parameters that are of only minor present interest and are represented by $\theta_{1}$ and $\theta_{2}$ in the two equations. Although it is not necessary to present the model in two different equations, this is done here to separate the processes and to simplify the discussion. The variable $r_{n}$ has no particular conceptual status, but is merely a device to achieve the separation. In general, the strategy of this sort of model is to generate a value of $p_{n+1}$, the probability of a response occurring on trial $n+1$, as a function of $p_{n}$, the probability of a response occurring on trial $n$. The first equation represents the effect of the temporal contiguity of the key and feeder on this trial. Notice that the change in the probabiltiy of responding depends on four quantities, all of which vary between zero and one. Two of these have already been mentioned, namely, $\mathrm{p}_{\mathrm{n}}$ and $\theta_{1}$. Each of the remaining two quantities is based on a particular principle. The quantity $a$ is the parameter that represents the similarity of the key and the feeder; the value of $a$ is greater the greater their similarity, and when $a$ is larger, the increment in probability from $p_{n}$ to $p_{n+1}$ is larger. This is equivalent to saying that the effectiveness of the temporal pairing increases with the similarity between key and feeder.

The quantity $p^{\prime}$ represents the extent to which the other key predicts food. Hence, the quantity $\left(1-p^{\prime}\right)$ represents the extent to which the other key does not predict food; thus, if the other key is a good predictor, this quantity is small and the increment to $p_{n}$ is small.

The second equation depicts processes that occur during pecking in the feeder. The pecks become conditioned to the cues of the feeder and, insofar as the feeder shares cues with a key, the probability of pecking this key is further increased. The extent to which the feeder shares the cues of the key is, again, just the value of the similarity parameter, a.

Table 4 shows the results of using the model to predict, for each key, the number of trials it is pecked in a session. The first line displays the empirical results, the mean number of trials each key is pecked in the three kinds of sessions. Least squares fits to these data of each of five submodels are shown in the remainder of the table. The five submodels were generated by leaving out one or another of the three processes: the type of generalization in the first equation (B), overshadowing (O), and the type of generalization of the second equation (G). The process $\mathrm{G}$ alone, on the second line from the bottom, accounts for $41 \%$ of the variance. This is not a good fit, and, for the third column pair, is even in the wrong direction. Comparing $G \& B$ with $G$ alone and $G \& B \& O$ with $G \& O$ alone suggests the relative contribution of $B$; $B$ does a substantial amount of work. In the first comparison, the variation accounted for goes from 
Table 4

Fit of Several Models to Mean Trials Pecked Per Session

\begin{tabular}{|c|c|c|c|c|c|c|c|c|c|c|c|}
\hline & \multicolumn{4}{|c|}{ Parameter Values } & \multicolumn{2}{|c|}{ None } & \multicolumn{2}{|c|}{$\begin{array}{c}\text { Other Feeder } \\
+ \text { Keys }\end{array}$} & \multicolumn{2}{|c|}{$\begin{array}{c}\text { Other Feeder } \\
\text { Only }\end{array}$} & \multirow{2}{*}{$\begin{array}{c}\text { Percent of } \\
\text { Variance } \\
\text { Accounted } \\
\text { For } \\
\end{array}$} \\
\hline & a & $\mathbf{a}^{\prime}$ & $\theta_{1}$ & $\theta_{2}$ & Sim & Dis & $\operatorname{Sim}$ & Dis & Sim & Dis & \\
\hline $\begin{array}{l}\text { Empirical } \\
\text { Theoretical }\end{array}$ & & & & & 28.5 & 1.1 & 8.9 & 39.0 & 14.0 & 8.3 & \\
\hline $\begin{array}{l}\text { G\&B\&O } \\
\text { G\&B } \\
\text { G\&O } \\
\text { G }\end{array}$ & $\begin{array}{l}.74 \\
.90 \\
.82 \\
.78\end{array}$ & $\begin{array}{l}.02 \\
.01 \\
.01 \\
.01\end{array}$ & $\begin{array}{l}.020 \\
.015 \\
.005 \\
.005\end{array}$ & $\begin{array}{l}.005 \\
.005 \\
.010 \\
.010\end{array}$ & $\begin{array}{l}23.7 \\
23.4 \\
17.8 \\
17.5\end{array}$ & $\begin{array}{l}0.7 \\
0.6 \\
5.0 \\
6.2\end{array}$ & $\begin{array}{r}6.3 \\
13.2 \\
14.9 \\
18.7\end{array}$ & $\begin{array}{l}38.8 \\
34.8 \\
29.9 \\
29.0\end{array}$ & $\begin{array}{l}19.9 \\
21.9 \\
11.5 \\
13.1\end{array}$ & $\begin{array}{r}9.7 \\
10.7 \\
24.9 \\
24.3\end{array}$ & $\begin{array}{l}94 \\
87 \\
47 \\
41\end{array}$ \\
\hline None $\left(\theta_{1}=\theta_{2}\right)$ & & & .015 & .015 & 14.4 & 14.4 & 24.4 & 24.4 & 14.4 & 14.4 & 15 \\
\hline
\end{tabular}

$41 \%$ to $87 \%$; the second, from $47 \%$ to $94 \%$. The overall fit improves, but the notable effect is in turning the third column pair around to the correct direction.

To evaluate the role of overshadowing, compare G\&O to $G$ alone and G\&B\&O to G\&B alone. In the first comparison, the variation accounted for goes from $41 \%$ to $47 \%$; in the second, from $87 \%$ to $94 \%$. Adding the overshadowing process leaves the two outside column pairs virtually unchanged; its main effect is in the middle pair, reducing pecking on the similar key and increasing pecking on the dissimilar key.

Each of these submodels has the same number of parameters free for fitting: namely, a for the similar key, a' for the dissimilar key, $\theta_{1}$ and $\theta_{2}$. An explicit model incorporating all three processes does the best job of fitting these data. If any of these processes operated at all in the present experiment, it is reasonable to conclude that they all did.

\section{REFERENCE NOTE}

1. Fisher, M. A. A model predicting attentional effects without an explicit attention response. Paper presented at Psychonomic Society meeting. St. Louis, 1976.

\section{REFERENCES}

Brown, P. L., \& Jenkins, H. M. Auto-shaping of the pigeon's key-peck. Journal of the Experimental Analysis of Behavior, 1968, 11, 1-8.

Downing, K., \& NeURinger, A. Autoshaping as a function of prior food presentations. Journal of the Experimental Analysis of Behavior, 1976, 26, 463-469.

Gamzu, E. R., \& Williams, D. R. Associative factors underlying the pigeon's key pecking in autoshaping procedures. Journal of the Experimental Analysis of Behavior, 1973, 19, 225-232.

Rescorla, R. A. Informational variables in Pavlovian conditioning. In G. H. Bower (Ed.), Psychology of learning and motivation (Vol. 6). New York: Academic Press, 1972.

WAGNer, A. R. Stimulus selection and a "modified continuity theory." In G. H. Bower \& J. T. Spence (Eds.), Psychology of learning and motivation (Vol. 3). New York: Academic Press, 1970.

(Received for publication January 29, 1977.) 